Klinik Araştırma / Clinical Research

\title{
Çocukluk çağı malign baş-boyun tümörlerinin retrospektif incelenmesi
}

\author{
Retrospective analysis of childhood cancer of the head and neck
}

\author{
Meral Özfındık ${ }^{a}$, Murat Elli ${ }^{\text {b* }}$, Ayhan Dağdemir ${ }^{a}$ \\ ${ }^{a}$ Ondokuz Mayıs Üniversitesi, Tıp Fakültesi, Çocuk Sağliğl ve Hastalıkları AD, Samsun \\ ${ }^{b}$ Ondokuz Mayıs Üniversitesi, Tıp Fakültesi, Çocuk Onkoloji BD, Samsun
}

Çocuk Onkoloji BD,

Kurupelit, Samsun

e-posta: ellimurat@yahoo.com

\section{Anahtar Kelimeler: \\ Baş-boyum tümörü \\ Çocukluk çağı \\ Lenfoma \\ Yumuşak doku sarkoma \\ Epitelyal tümörler}

\begin{abstract}
The head and neck is a region that different and several neoplasms are established. Five to ten percent of primary childhood tumors are located on head and neck. In about $25 \%$ of childhood tumors, complaints or physical findings, dealing with head-neck involvement are found. In this retrospective study we investigated the children with primary head-neck tumors followed by Pediatric Oncology Department. Among 100 patients, 73 (73\%) had lymphoreticular tumors, $8(8 \%)$ had soft tisue sarcomas, $18(18 \%)$ had ephitelial tumors, and only one (1\%) had bone tumor.

J. Exp. Clin. Med., 2011; 28:49-54
\end{abstract}

\section{Keywords:}

Head-neck tumors

Childhood

Lymphoma

Soft tisue sarcoma

Ephitelial tumors

(C) 2011 OMU All rights reserved

\section{Giriş}

Boyun, çok değişik ve çok sayıda neoplazmın görüldüğü ve lenfatik ağın en yoğun olduğu vücut bölgesidir. Boyunda kitle farklı tıp disiplinlerinin ortak ilgi alanını oluşturan ve oldukça sık görülen bir patolojik durumdur. Çocukluk çağı kanserlerin \%30'unu lösemiler ve kalan \%70'ini de solid tümörler oluşturur (Hudson ve ark., 2006). Çocukların primer maliyn tümörlerinin yaklaşık \%5-10'u baş-boyun bölgesinden kaynaklanır. Çocukluk çağı malignitelerinin de yaklaşık \%25'inde baş-boyun bölgesini ilgilendiren yakınma veya bulgular eşlik eder (Whittemore ve ark., 2003). Bu çalışmada Çocuk Onkoloji Bilim Dalı tarafından izlenen baş ve boyun bölgesi yerleşimli maliyn tümör olgularının epidemiyolojik, klinik ve laboratuvar özellikleri, uygulanan tedavi ve sonuçları ve geç komplikasyonlar araştırıldı.

\section{Hasta ve Yöntem}

Çalışmamıza Çocuk Onkoloji Bilim Dalı'nda tanı almış olan 845 hasta içerisinde baş boyun bölgesinde yerleşim gösteren maliyn tümörlü 100 hastanın dosyası geriye yönelik olarak incelendi. Çalışmaya intrakranial tümörler, retinoblastom ve primer yerleşim yeri abdomen ve toraks olan lenfomalar dahil edilmedi. Hastaların denografik verileri, başvuru yakınmaları, fizik muayene bulguları, kitlenin yerleşim yeri, kitle 
boyutu, kitle hacmi, yakınmaların süresi, tedaviye başlama tarihleri, başvuru anındaki laboratuvar bulgular, geç komplikasyonlar ve hastaların mevcut son durumları kaydedildi.

Morfolojik tanımlamalar için ICD-O-3 kodları kullanıldı, kanser sınıflaması için ICCD- 3 kodları kullanıldı. Hastalar tanı aldıkları yaş gruplarına göre $0-<1,1-4,5-9,10-14,15-18$ olmak üzere toplam beş grupta incelendi.

Veriler SPSS 15 for Windows ile analiz edildi. Tanımlayıcı istatistikler yanında sayısal verilerin karşılaştırılmasında parametrik olanlarda student-t testi, parametrik olmayanlarda Mann-Whitney-U testi kullanıldı.

Nitelikli verilerin karşılaştırlmasında ki-kare testi yapıld1. Sağkalım analizi Kaplan-Meier sağkalım analizine göre yapıldı; sağ kalım karşılaştırması ise log-rank analizi ile yapildi.

\section{Bulgular}

Çocuk Onkoloji Bilimdalı tarafından izlenen 845 hasta içinde 100'ünün $(\% 11,8)$ baş ve boyun bölgesinde yerleşim gösteren malign tümör nedeni ile tedavi edildiği saptandi. Hastalardan 3'ü (3 k1z) (\%3) 1980-1989, 25'i (10 k1z, 15 erkek) (\%25) 1990-1999, 72'si (23 kız, 49 erkek) (\%72) 20002009 yılları arasında tanı almıştı. 1980-1989'da başvuran hastaların 3'ü kızdı. 1990-1999'da başvuranların 10'u kız, 15'i erkekti. 2000-2009 yılları arasında başvuranların 23 ü k1z 49'u erkekti.

Tüm baş-boyun tümörlü hastaların \%33'ünü kızların $(n=33) \% 67$ 'sini erkeklerin (n=67) oluşturduğu saptandı. Erkek k1z oranı 2,0/1 idi. Hastaların 4'ü (2 kı/ 2 erkek) $0-<1$ yaş; 20'si (6 kız /14 erkek); 1-4 yaş, 31'i (11 kı/ 20 erkek); 5-9 yaş, 35'i (10 kı/ 25 erkek) 10-14 yaş, 10’u (4 kız/6 erkek) 15-18 yaş grubundaydı (Şek. 1 ).

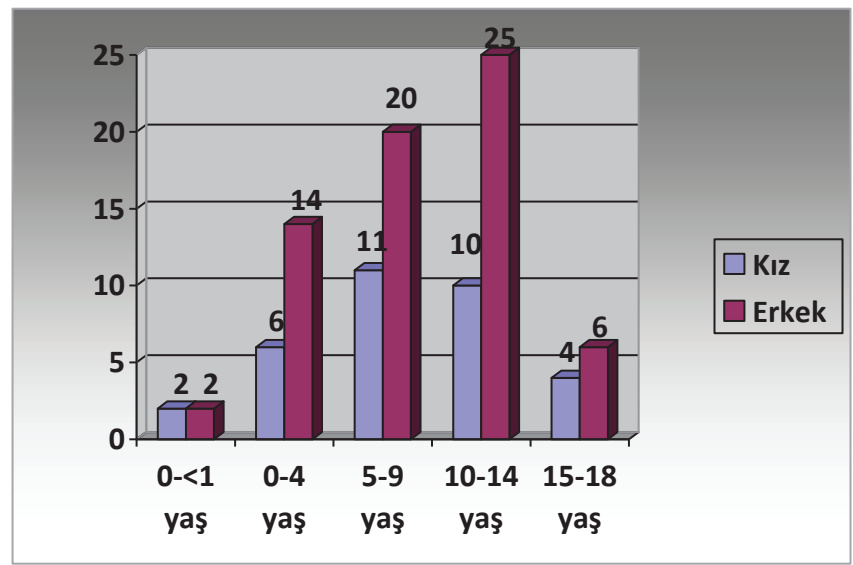

Şek. 1: Yaş gruplarına göre hasta sayıları dağılımı

Ortalama tanı yaşı kızlarda 9,0 yıl; erkeklerde 8,3 yıldı. Ortanca tanı yaşı kızlarda 9,3 (en büyük 16,8 yıl; en küçük 2 ay); erkeklerde ise 7,9 yıldı (en büyük 16,6 yıl; en küçük 1 ay) ( $p>0,05)$. Hastaların \%82'si $(n=82)$ boyunda şişlik ile başvurmuştu. Ayrıca \%2'si (n=2) yüzde; \%1'i (n=1) saçlı deride; \%2'si (n=2) yanakta; \%3'ü gözde; \%4'ü $(n=4)$ çenede; $\% 1$ 'i damakta ve \%1'i (n=1) dudakta şişlik yakınmasıyla başvurmuştu. Diğer nadir yakınmalar ise $\% 1$ ' $i(n=1)$ yutma güçlüğü, \%1'i (n=1) burun tıkanıklığı, \%1'i (n=1) boğaz ağrıs1, $\% 1$ 'i $(n=1)$ kulakta kitleydi.

Yakınma süresi hastaların \%33'ünde (n=33) 3ay-6 ay, \%31'inde $(n=31)$ 1ay-3 ay, \%6'inda $(n=6)$ 1gün-1ay, $\% 17$ 'sinde $(n=17) 6$ aydan fazlaydı. Hastaların \%35'inde $(\mathrm{n}=35)$ sistemik yakınması vardı. Tüm hastaların \%12'sinde $(n=12)$ ateş, \%13'ünde ( $n=13)$ kilo kaybı; \%10'unda $(n=10)$ gece terlemesi saptandi.

Olguların \%3' $\ddot{\mathrm{u}}(\mathrm{n}=3)$ baş boyun bölgesinde fizik incelemede saptanan kitle metastatikti; servikal lenf bezlerine metastaz vard1. Bunlardan 2 tanesi tiroit kanseri, 1 tanesi nazofarinks kanseriydi. \%97'si (n=97) primer kitleydi. Hastaların fizik muayenesinde patolojik olarak 24 olguda hepatosplenomegali (HSM) saptanmıştı. \%9'unda hepatomegali, \%3' ünde $(n=3)$ splenomegali, \%12'sinde $(n=12)$ HSM saptand1. Hastaların \%63'üne ( $\mathrm{n}=63)$ kemik iliği aspirasyonu yapılmıştı ve bunlardan \% 7,9'unda tutulum saptanmıştı. Tanısal işlem olarak hastaların 94'üne (\%94) eksizyonel lenf nodu biyopsisi yapılmıştı, 6 olguda (\%6) kitleden insizyonel biyopsi yapılmiştı.

Hasta tanıları ICCD (International Classification of Childhood Cancer) sinıflamasına göre yapıldı. Buna göre hastaların 73'ü (\%73) lenfoma ve RES tümörü, 8'inde (\%8) yumuşak doku sarkomu (YDS), 18'inde (\%18) malign epitelyal tümörler, 1'inde (\%1) kemik tümörü saptandı (Şek. 2). Lenfoma ve retiküloendotelyal sistem tümörlü (RES) hastaların 50'si erkek (\%68,4); 23 ‘ü $(\% 31,5)$ kızd1. Yumuşak doku sarkomlarının (YDS) 4’ü kız, 4 'ü erkekti (\%50). Epitelyal tümörlerin 5'i $(\% 27,7)$ k1z, 13’ü $(\% 72,2)$ erkekti, 1 kız hasta

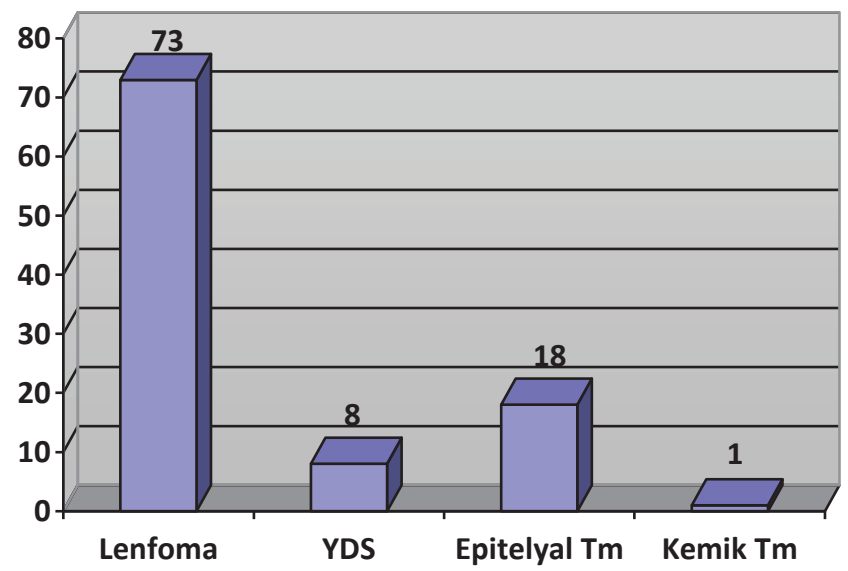

Şek. 2: Hastaların tanılarına göre dağılımı

Tablo 1: Hastaların ICCD-3 tanılara göre dağılımı

\begin{tabular}{lccc} 
Tanı & Erkek & Kız & Toplam \\
\hline Lenfoma-RES Tm & $50(\% 68,5)$ & $23(\% 31,5)$ & 73 \\
YDS & $4(\% 50,0)$ & $4(\% 50,0)$ & 8 \\
Epitelyal TM & $13(\% 72,0)$ & $5(\% 28,0)$ & 18 \\
Kemik Tm & & $(1 \% 1,0)$ & 1 \\
\hline TOPLAM & $\mathbf{6 7}(\mathbf{\% 6 7 , 0 )}$ & $\mathbf{3 3}(\mathbf{\% 3 3 , 0 )}$ & $\mathbf{1 0 0}$
\end{tabular}

Tablo 2: Hastaların ICCD-3 alt grup tanılarına göre dağılımı

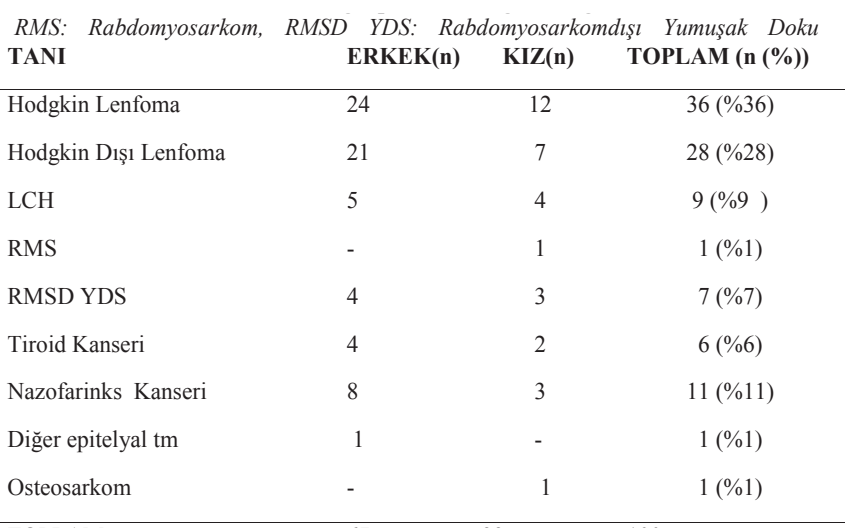

\begin{tabular}{lll}
\hline TOPLAM & 67 & 33
\end{tabular}

Sarkomu, LCH: Langerhans Hücreli Histiyositozis 
Tablo 3 : Hastaların histopatolojilerine göre dağılımı

\begin{tabular}{|c|c|c|c|c|}
\hline HISSTOPATOLOJI & ICD-O-3 & ERKEK & KIZ & TOPLAM \\
\hline Lenfositten zengin HL & 9651.3 & - & 2 & $2(\% 2,2)$ \\
\hline Noduler sklerozan HL & 9663.3 & 5 & 3 & $8(\% 8,9)$ \\
\hline Lenfositten fakir HL & 9653.3 & 3 & 1 & $4(\% 4,5)$ \\
\hline Karıșık hücreli HL & 9652.3 & 13 & 6 & $19(\% 21,1)$ \\
\hline Burkitt lenfoma & 9687.3 & 7 & 2 & $9(\% 10)$ \\
\hline Büyük hücreli B lenfoma & 9680.3 & 3 & 1 & $4(\% 4,5)$ \\
\hline İnterfolliküler tip lenfoma & 9695.3 & - & 1 & $1(\% 1,1)$ \\
\hline Yüksek maliyn lenfoma & 9670.3 & 6 & 3 & $9(\% 10)$ \\
\hline Anaplastik büyük hücreli lenfoma & 9714.3 & 1 & 2 & $3(\% 3,4)$ \\
\hline Öncül T lenfoblastikLenfoma & 9729.3 & 1 & - & $1(\% 1,1)$ \\
\hline T hücreli lenfoma & 9702.3 & 1 & - & $1(\% 1,1)$ \\
\hline Folliküler karsinom & 8330.3 & - & 1 & $1(\% 1,1)$ \\
\hline Papiller karsinom & 8340.3 & 4 & 1 & $5(\% 5,6)$ \\
\hline Maliyn mezankimal tümör & 8800.3 & 4 & 1 & $5(\% 5,6)$ \\
\hline Maliyn rabdoid tümör & 8900.3 & - & 1 & $1(\% 1,1)$ \\
\hline Embriyonel sarkom & 8910.3 & - & 1 & $1(\% 1,1)$ \\
\hline Hemanjioperostom & 9150.3 & 1 & - & $1(\% 1,1)$ \\
\hline Fibrosarkom & 9330.3 & - & 1 & $1(\% 1,1)$ \\
\hline Primitif nöroektodermal tümör & 9364.3 & - & 1 & $1(\% 1,1)$ \\
\hline Eozinofilik granulom & 9752.1 & 1 & & $1(\% 1,1)$ \\
\hline Langerhans hücreli histiositoz & 9753.1 & 4 & 4 & $8(\% 8,8)$ \\
\hline Nonkeratinize epidermoidkarsinom & 8073.3 & 3 & 1 & $4(\% 4,4)$ \\
\hline TOPLAM & & 57 & 33 & $90(\% 100)$ \\
\hline
\end{tabular}

osteosarkomdu (Tablo 1 ve 2).

Tablo 4: Tümörlerin yerleşim yerlerine göre dağılımı

\begin{tabular}{lll}
\multicolumn{1}{c}{ LOKALIZASYON } & ICD-O-3 & SAYI(n/\%) \\
\hline Servikal lenf nodu & C77 & $61(\% 61)$ \\
Nazofarinks & C11.9 & $12(\% 12)$ \\
Kafa kemikleri & C41 & $7(\% 7)$ \\
Tiroid & C73.9 & $6(\% 6)$ \\
Mandibula & C41.1 & $3(\% 3)$ \\
Tonsil & C09.9 & $3(\% 3)$ \\
Orofarinks & $\mathrm{C} 10.9$ & $2(\% 2)$ \\
Maksiller sinüs & $\mathrm{C} 31.0$ & $1(\% 1)$ \\
Dış kulak yolu & $\mathrm{C} 44.2$ & $1(\% 1)$ \\
Yanak & $\mathrm{C} 49.0$ & $1(\% 1)$ \\
Dudak & $\mathrm{C} 00.9$ & $1(\% 1)$ \\
Yaygıı & & $2(\% 2)$ \\
\hline TOPLAM & & $100(\% 100)$
\end{tabular}

Doksan hastanın histopatoloji raporuna ulaşıldı ve ICDO-3 sınıflamasına göre kodlama yapıldı. En sık görülen histopatoloji karışık hücreli Hodgkin lenfomaydı. Hastaların histopatolojilerine göre dağılımı Tablo 3'de verilmiştir. Tümörlerin yerleşim yerleri ICD-O-3 topografik kodlara göre yapıldı en sık \%61 ile servikal lenf bezler tutulmuştu. Diğer yerleşim bölgeleri Tablo 4'te verildi. Patolojik boyuttaki lenf nodlarının 2'si $(\% 3,2)$ submental, 5'i submandibular, 9'u $(\% 14,7)$ supraklavikular, 1'i $(\% 1,6)$ postaurikular, 44'ü $(\% 72,1)$ servikal lenf nodlarından kaynaklanıyordu.

$0-<1$ yaş grubunda olan hastaların 2'si $(\% 2,7)$ lenfoma ve diğer retiküloendotelyal tümör, 1'i $(\%$ 12,5) yumuşak doku sarkomu, 1'i $(5,5)$ malign epitelyal tümördü. 1-4 yaş arasındaki hastaların 18 'i $(\% 32,8)$ lenfoma ve diğer retiküloendotelyal tümör, 2'si (\%25) yumuşak doku sarkomuydu. $\mathrm{Bu}$ yaş grubunda malign epitelyal tümör yoktu. 5-9 yaş arasindaki hastaların 24 'ü $(\% 32,8)$ lenfoma ve diğer retiküloendotelyal tümörler, 3‘ü $(\% 37,5)$ yumuşak doku sarkomuydu, 4'ü $(\% 22,2)$ malign epitelyal tümördü. 10-14 yaş arasındaki hastaların 24'ü $(\% 32,8)$ lenfoma ve diğer retiküloendotelyal tümörler, 2'si (\%25) yumuşak doku sarkomu, 8'i $(\% 44,4)$ epitelyal tümördü ve 1 'i (\%1) kemik tümörüydü. 15-18 yaş arasındaki hastaların 5'i $(\% 6,8)$ lenfoma ve retiküloendotelyal sistem tümörüydü, 5'i (\%27,7) malign epitelyal tümördü (Tablo 5). Yumuşak doku sarkomları en sık 5-9 yaş arasında
Tablo 5 :Yaş gruplarına göre tümörlerin dağılımı

\begin{tabular}{llllc}
$\begin{array}{l}\text { Yaș } \\
\text { grupları }\end{array}$ & Lenfoma & YDS & $\begin{array}{l}\text { Epitelyal } \\
\text { tümör }\end{array}$ & $\begin{array}{c}\text { Kemik } \\
\text { tümör }\end{array}$ \\
\hline $\mathbf{0 - < 1}$ & 2 & 1 & 1 & - \\
$\mathbf{1 - 4}$ & 18 & 2 & - & - \\
$\mathbf{5 - 9}$ & 24 & 3 & 4 & - \\
$\mathbf{1 0 - 1 4}$ & 24 & 2 & 8 & 1 \\
$\mathbf{1 5 - 1 8}$ & 5 & - & 5 & - \\
\hline TOPLAM & 73 & 8 & 18 & 1
\end{tabular}

görülmüştü, malign epitelyal tümör ise en sık 10-14 yaş arasinda görülmüştü.

Hastalarda tümörlerin yerleşim yerlerine göre tümörlerin dağılımı Tablo 6'da verilmiştir. 10 Olgu $(\% 9,0)$ kız; diğer 10 olgu $(\% 90,9)$ erkekti. 5 kişide servikal lenf bezlerine, 2 kişide akciğere, 1 kişide karaciğere, 2 kişide kemik, 1 kişide testise metastaz vardi.

Tablo 6 : Tümör lokalizasyonuna göre kanser türlerinin dağ 11 ım1

\begin{tabular}{lllccc} 
& $\begin{array}{l}\text { ICD-O-3 } \\
\text { topografi } \\
\text { kodu }\end{array}$ & Lenfoma ve & YDS(n) & $\begin{array}{l}\text { Maliyn } \\
\text { epitelyal } \\
\text { tümör(n) }\end{array}$ & $\begin{array}{l}\text { Kemik } \\
\text { Tümörü } \\
\text { (n) }\end{array}$ \\
\hline $\begin{array}{l}\text { Servikal lenf nodu } \\
\text { Nazofarinks }\end{array}$ & C77 & 59 & 2 & - & - \\
Tiroid & C73.9 & - & - & 10 & - \\
Kafa kemikleri & $\mathrm{C} 41$ & 5 & - & 6 & - \\
Dudak & $\mathrm{C} 00.9$ & - & - & 1 & 1 \\
Tonsil & $\mathrm{C} 09.9$ & 3 & 1 & - & - \\
Orofarinks & $\mathrm{C} 10.9$ & - & - & - & - \\
Maksiller sinüs & $\mathrm{C} 31.0$ & - & 2 & - & - \\
Mandibula & $\mathrm{C} 41.1$ & 1 & - & 1 & - \\
Diş kulak yolu & $\mathrm{C} 44.2$ & - & 2 & - & - \\
Yanak & $\mathrm{C} 49.0$ & 1 & 1 & - & - \\
Yaygin & -- & 2 & - & - & - \\
\hline TOPLAM & & 73 & - & - & - \\
\hline
\end{tabular}

Takiplerine ve kontrollerine devam eden toplam 100 hastanın 10'unun (\%10) tedavisinin devam ettiği; 82'sinin (\%82) hastalıksız hayatta, 1'inin (\%1) başka merkezde takipli olduğu belirlendi. Hastalardan biri takiplerine gelmemişti ve primer hastalığı nedeni ile kaybedilmişti, diğer hasta ise mental retarde idi ve sekonder hastalık nedeni ile eksitus olmuştu. Diğer hastalar progresif hastalık nedeni ile eksitus olmuşlardi.

Hastaların 31'inde (\%31) geç dönem komplikasyon gelişmişti. Bu olguların 16'sında $(\% 53,3)$ obezite mevcuttu (11 tanesi erkek, 5 tanesi kıdı). Nazofarinks kanseri tanısı olan 1 hastada (\%1) işitme kaybı, 2 hastada (\%2) yutma güçlügü, 6 hastada (\%6) hipotiroidi gelişmişti, bu hastaların hepsi boyun bölgelerine radyoterapi almışlardı. Nazofarinks kanseri bir erkek hastada hem azospermi hem de hipotiroidi mevcuttu; boyun bölgesine 4600 cGy radyoterapi almıştı ve sistemik 14 kür siklofosfamid, vinkristin ve aktinomisin almıştı. Bir hastada (\%1) periferik nöropati gelişmişti hasta 2 COPP ve 3 OPPA protokolleri içerisinde toplam 9 kez yüksek doz vincristin almıştı, 1 hastada (\%1) oral kavitede darlık ve aynı zamanda hipotiroidi vard1, 1 erkek hastada (\%1) hipersplenizm gelişmişti.

Hodgkin dişı lenfoma tanısı ile izlenen bir kız hastada (\%1) ikincil malignite olarak akut myeloid lösemi gelişmişti. 
Hasta BFM-90 kemoterapi protokolü alırken tanısından 9 ay sonra ikincil malignite gelişti. NHL tanısı olan diğer bir kız hastada (\%1) tedavi bitiminden 4 ay sonra hastalık tekrarlamıştı. Relaps tedavisinden 9 ay sonra hastalık ikinci kez tekrarlamıştı.

Hastaların ortalama takip süresi $41,9 \pm 47,36$ ay; ortanca takip süresi 24,87 ay (En kısa 0,1; en uzun 248,9 ay) olarak saptandı. Hastalarımızın tümü için genel sağ kalım $\% 91,2 \pm 0,32$ idi. Tanılarına göre genel sağ kalım oranı ise; lenfoma ve diğer RES tümörlerinde $\% 96,8 \pm 0,22$, yumuşak doku sarkomlarında $\% 87,5 \pm 11,7$, malign epitelyal tümörlerde $\% 78,0 \pm 11,4$ 'tü. Osteosarkom tanısı ile izlediğimiz kız hastamiz progresif hastalık nedeni ile 4 aylık izlem sonunda eksitus olmuştu. Log-rank analizinde, sağkalım açısından gruplar arasında fark saptanmadı $(\mathrm{p}>0,05)$. Şekil 3 'te tüm hastaların takip sürelerine göre sağkalım grafiği gösterildi.

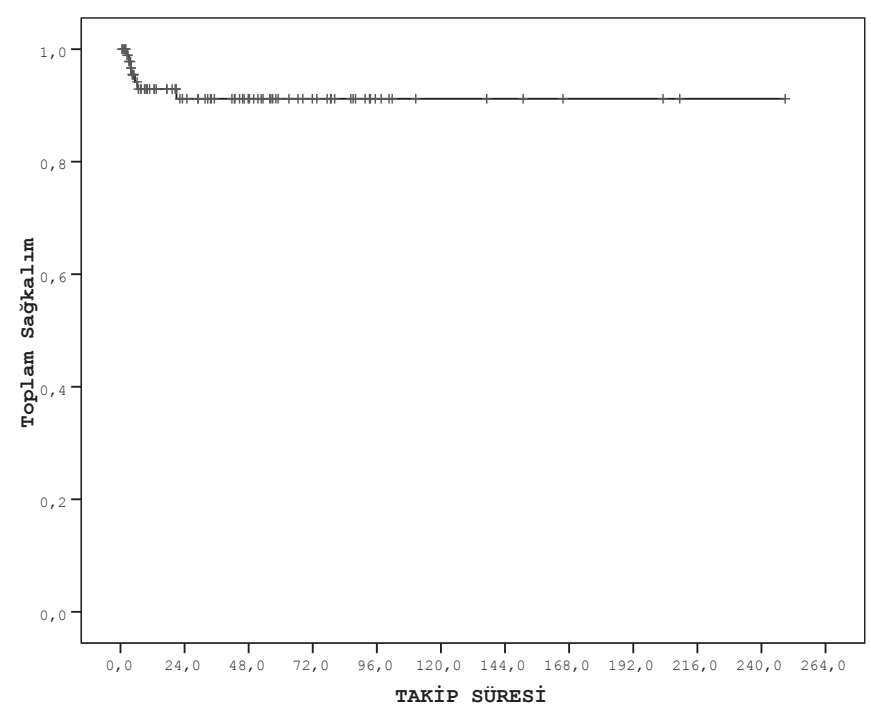

Şek. 3: Olgularımızın sağkalım analizi

\section{Tartışma}

Çalışmamızda çocukluk çağı malign tümörü tanısı ile izlenen hastalar içinde primer tümör yerleşimi baş ve boyun bölgesi olan hastaların verileri geriye yönelik olarak incelendi. Tümörün kaynaklandığı lokalizasyon, hastaların başvuru yakınmaları, fizik muayene bulguları, histopatolojik tanılar, lokalizasyona göre tümör çeşitleri, tümör çeşitlerinin yaş gruplarına göre dağılımı ve hastalarımızın sağ kalım analizleri yapıldı. Çalışmamız çocukluk çağı baş ve boyun tümörlerini erkek-kız cinsiyete, yaş gruplarına, histopatolojisine, lokalizasyona göre Türkiye' de değerlendiren ilk çalışmadır. Toplam 845 onkoloji hastası içerisinde $100(\% 11,8)$ olguda primer hastalık bölgesi baş ve boyun kaynaklıydı. Gosebath ve arkadaşlarının Almanya Çocukluk Çağı Kanser Veri tabanını kullanarak yaptıkları çalışmada 1980-2004 yılları arasında tanı almış 15 yaş altında 5078 maliynensi incelenmiş bunların 370 tanesi $(\% 7,3)$ baş ve boyundan kaynaklandığ saptanmış. Çalışmaya intrakranial tümörler ve retinoblastom dahil edilmemişti (Gosepath ve ark., 2007). Albright ve arkadaşları 1973-1996 yılları arasında tanı almış 24960 olguyu ulusal kanser enstitüleri gözlemleri, epidemiyoloji ve sonuç tümör kayıtları veri tabanından (SEER) geriye yönelik olarak değerlendirmiş. $\mathrm{Bu}$ malignensilerden $3050(\% 12,2)$ tümör baş ve boyun kaynaklıymış. Ancak bu çalışmaya retinoblastom dahil edilmişti (Albrighti ve ark., 2002). Hacettepe
Üniversitesi'nde Akyüz ve ark.'nın yaptığı çalışmada 19712002 yılları arasında takip edilen 6176 kanserli olgunun 747 (\%12) tanesi baş ve boyun bölgesi kaynaklıydı. Bu çalışmaya intrakraniyal tümörler ve retinoblastom dahil edilmemişti (Akyüz ve ark., 2003). İran'da Bijan Khademi ve ark.'nın yaptığı çalışmada üç büyük referans hastanenin kanser kayıt veri tabanı kullanılarak 2000-2007 yılları arasinda tanı alan 1493 hasta 19 yaş altındaydı ve bunlardan 152'si (\%10,1) baş ve boyundan kaynaklanıyordu (Albright ve ark., 2002). Akyüz C, Khademi'nin ve Albright'ın çalışmasındaki baş ve boyun tümörü oranı bizim çalışmamızla uyumluydu.

Gosebath ve ark.'nın yaptığı çalışmada kız hasta sayısı $171(\% 46,2)$, erkek hasta sayısı $199(\% 53,7)$, erkek/ kız oranı 1.2/1 di (Gosepath ve ark., 2007). Albright ve ark.'nın çalışmasında 1432 erkek (\%47) ve $1618(\% 53)$ k1z hasta vard1 (Albright ve ark., 2002). Khademi ve ark.'nın yaptığı çalışmada 99 erkek (\%65), 53 k1z (\%35) hasta mevcuttu (Khademi ve ark., 2009). Hacettepe Üniversitesi'nin yaptığı çalışmada erkek kız sayısı belirtilmemişti, sadece hastaların 10-14 yaş grubunda daha fazla olduğu ve erkek sayısının fazla olduğu bulunmuştu (Akyüz ve ark., 2003). Bizim çalışmamızda 33 kı1 (\%33), 67 (\%67) erkek hastamız vardı.

J. Gosebath ve arkadaşlarının yaptığı çalışmada 15 yaş altı olgular alınmıştı. Olguların en sık görüldüğü yaş grubu 10-14 yaş grubuydu ve bizim çalışmamızla benzerdi. B. Khademi ve arkadaşlarının yaptığ zim çalışmamız ile aynıydı ancak İran'dan yapılan çalışmada olguların en sık görüldüğü yaş grubu 15-18 yaş iken bizim çalışmamızda 10-14 yaştı (Gosepath ve ark., 2007; Khademi ve ark., 2009) (Tablo 7).

Tablo 7: Yaş gruplarının çalışmalardaki dağılımı

\begin{tabular}{llll} 
& Çahșmamiz & J. Gosetbath (54) & B. Khademi (57) \\
\hline $\mathbf{0}<\mathbf{l}$ & 4 & 9 & $\ldots \ldots$ \\
$\mathbf{1 - 4}$ & 20 & 81 & 20 \\
$\mathbf{5 - 9}$ & 31 & 109 & 34 \\
$\mathbf{1 0 - 1 4}$ & 35 & 171 & 46 \\
$\mathbf{1 5 - 1 9}$ & 10 & $\ldots \ldots$. & 52 \\
\hline TOPLAM & $\mathbf{1 0 0}$ & $\mathbf{3 7 0}$ & $\mathbf{1 5 2}$
\end{tabular}

Çalışmamızda baş boyun bölgesinde kitle yakınması ile başvuran hastaların yakınma süreleri en sık 3ay- 6ay arasında bulunmuştu (Tablo 6). Benzer çalışmalarda bununla ilgili veri yoktu. Hacettepe Üniversitesi'nin yapmış olduğu çalışmada \%40,1 (300) yüzde oranı ile lenfomalar ilk sıradaydı, \%28,6 (213) YDS ve \%19,3 (144) malign epitelyal tümördü (Akyüz ve ark., 2003). Gosebath ve ark'nın yaptığı çalışmada en sık görülen malignite çeşidi 147 olgu $(\% 39,7)$ ile yumuşak doku sarkomlarıyd1, malign epitelyal tümörler 125 olgu ile $(\% 33,8)$ ikinci sıklıkta, lenfoma ve diğer RES tümörleri 79 olgu $(\% 21,4)$ ile üçüncü sıklıktaydı (Gosepath ve ark., 2007). Gosebath ve arkadaşlarının yaptığ çalışmada 84 olgu (\%55) ile lenfomalar ilk siradaydı, maliyn epitelyal tümörler 30 olgu (\%20) ile ikinci sıradaydı, 15 olgu (\%10) ile sarkomlar üçüncü sıradaydı ancak çalışmalarına benin lezyonları da dahil etmişlerdi (Khademi ve ark., 2009).

Albright ve arkadaşlarının yaptığ ve ark., 2002) benin lezyonlar çalışmaya dahil edilmemişti ancak retinoblastom ve nöral tümörler çalışmaya dahildi. 854 hasta (\%28) malign epitelyal tümörlerle ilk sıradaydı, 823 
hasta (\%27) lenfoma ile ikinci surada, YDS 366 hasta (\%12) ile üçüncü sıradaydı.

Bizim çalışmamızda olguların 73 tanesinde $(\% 73,7)$ lenfoma ve RES tümörü, 8 tanesinde $(\% 8,08)$ yumuşak doku sarkomu, 18 tanesinde $(\% 18,1)$ malign epitelyal tümör vard 1 ve bu sonuçlar Hacettepe Üniversitesi'nin yapmış olduğu çalışma ve İran'dan yapılan çalışma ile uyumluydu. Almanya ve ABD verilerinden farklı sonuçlar bulunmuştu. Gosebath ve ark.'nın yaptığ 1 çalışma ile farklı bulunmasının nedeni; tanı sırasında sistemik-yaygın hastalık olan lenfomalı olguların çalışma dışı bırakılması olabilir. Albright 'in yaptığı çalışmayla olan farklılığın ise adölesan kızlarda artmış tiroit kanserine bağlı olduğunu düşünmekteyiz.

Albright ve ark.'larının çalışmasında (Albrighti ve ark., 2002) tiroit kanseri 652 hastada $(\% 21,3)$ görülmüştü oysa bizim çalışmamızda 6 tiroit (\%6) kanserli hasta saptanmışt1. Bu hastalarda erkek cinsiyet üstünlüğü varken Albright ve arkadaşlarının sonuçlarında kız cinsiyet fazlalığı vardı bunun nedeni çalışmalarında geniş bir veri tabanının kullanılmasının olduğunu düşünmekteyiz. Yine aynı çalışmada lenfomalardan Hodgkin lenfoma daha fazlaydı ve erkeklerde daha fazla görülmüştü bu sonuçlar bizim çalışmamızla uyumluydu. Khademi ve arkadaşlarının yaptığı çalışmada Hodgkin dışı lenfoma daha fazla saptanmıştı. Hacettepe Üniversitesi'nin çalışmasında da Hodgkin lenfoma fazla saptanmıştı ve lenfomalarda erkek üstünlüğü görülmüştü.

ICD-O-3 sınıflamasına göre yapılan morfolojik sınıflamada en sık görülen morfoloji karışık hücreli lenfomaydı. Khademi ve ark'nın yaptıkları çalışmada en sık Burkitt lenfoma saptanmıştı, bizim çalışmamızda Burkitt lenfoma ikinci sıradaydı. Çalışmamızda lenfomalarda erkek cinsiyetin üstünlügü saptanmıştır. Bu bulgu tüm lenfomalarda beklendiği gibi ABD, Hacettepe üniversitesi, İran ve Almanya'da yapılan çalışmalar ile de benzerdir (Albrihgt ve ark., 2002; Gosepath ve ark., 2007; Akyüz ve ark., 2003; Khademi ve ark., 2009).

Çalışmamızda primer yerleşim lokalizasyonu en sık servikal lenf bezleri olarak saptanmıştı. Bu bulgu Hacettepe Üniversitesi, Khademi ve ark'nın yaptığı çalışma ile uyumluydu. Gosebath ve ark'nın yaptığı çalışmada en sık yerleşim yeri tiroit bezi olarak saptanmıştı. Diğer anatomik bölgelerde ise tümör dağılımı yapıldı. Ancak tümör grupları heterojen ve hasta sayısı sınırlı olduğundan karşılaştırma yapılamadı. Sayılar az olsa da servikal lenf bezi büyüklüğü ile başvuran hastalarda lenfoma, nazofarinks kanseri ve tiroit kanserinin ayırıcı tanıda düşünülmesi gereklidir. Ayrıca adölesan yaş grubunda tiroit bezi muayenesinin dikkatli yapılmasının gerektiğini düşünmekteyiz.

Radyoterapi alan hastalarda tiroit stimüle edici hormon düzeyinin ölçülmesi sonucunda hastalarda \%4-79 oranında hipotiroidi geliştiği belirlenmiştir. Preadölesan çocuklarda tiroit dokusu erişkinlerden daha hassastır. Radyoterapi dozu önemlidir. Boyun bölgesine radyoterapi alan çocuklarda doz
26 Gy altında ise tiroit bozukluğu gelişme riski \%17, radyoterapi dozu 26 Gy ve üzerinde ise risk \%78 bulunmuştur. Bir seride araştırıcılar biyokimyasal olarak kompanse hipotiroidili çocukların \%36'sında düzelme olduğunu belirlemişlerdir (Constine ve ark., 1984). Bizim hastalarımızın 6 tanesinde hipotiroidi gelişmişti, nazofarinks kanseri ve lenfoma tanısı olan hastalardı ve boyun bölgelerine radyoterapi almışlardı. Hodgkin lenfoma tanısı olan bir hastamızda azospermi gelişmişti. 6-8 kür MOPP kemoterapisinin uygulaması sonucunda adult veya pediatrik yaş grubundaki erken Hodgkin lenfomalı hastaların \%80-90'ında azospermi gelişmiştir (Anselmo ve ark., 1990). Hodgkin lenfoma tanısı konulduğu zaman hastaların \%30-40'1nda primer gonodal disfonksiyon olabilir. Bununla birlikte ileri yaştaki hastalarda eğer pelvik bölgeye radyoterapi ve özellikle alkile edici ajan içeren kemoterapi protokolü planlanıyorsa tedaviye başlamadan önce sperm saklanmalıdır.

Sekonder kanserler kemoterapi, radyoterapi ve kombine yaklaşımlarla tedavi edilen hastalarda geç olarak ortaya çıkan önemli bir yan etkidir, risk hastaya ait (yaş, cinsiyet, genetik) ve maligniteye ait (tümör lokalizasyonu, tümör biyolojisi yanıtı, tedavi modeli) olmak üzere multifaktöryeldir. Hastalığa ve tedaviye bağlı olarak gelişen immün bozuklukların karsinogenezise predispozisyon oluşturduğu düşünülmektedir. Kanser nedeniyle alkilleyici ajanlar ve topoizomeraz inhibitörleri alan hastalarda myeloid malignensiler başta olmak üzere ikincil kanser gelişimi riski artmaktadır. Özellikle baş boyun ve üst mediastene radyoterapi uygulanan hastalarda meme kanseri, tiroit tümörleri, lösemi, HDL gibi ikincil maliynite olasılığı daha belirgindir ((Hudson ve ark., 2006; Karayalcın ve ark 2000). Lenfoma tanısı ile izlediğimiz bir k1z hastamızda tedavi sırasında akut myeloid lösemi gelişti.

Hastalarımızın tanılarına göre sağ kalım oranları lenfoma ve diğer RES tümörlerinde \%98,1, yumuşak doku sarkomlarında \%85,7 malign epitelyal tümörlerde \%90,9'du. Log-rank analizinde, sağkalım açısından gruplar arasında fark saptan$\operatorname{mad}_{1}(\mathrm{p}>0,05)$.

Bizim çalışmamızdaki toplam olgu sayısının ve ikincil tümör sayısının az olmasının nedeni diğer ülkelerde yapılan çalışmalarda ulusal kanser veri tabanlarının kullanılması ve olgu sayılarının fazla olması, bizim çalışmamızda ise sadece çocuk onkoloji departmanımız tarafından takip edilen hastaların çalışmaya alınması ve çalışmalardaki tümör dahil etme kriterlerindeki farklılıklardan kaynaklandığını düşünmekteyiz. Türk Pediatri Onkoloji Grubu tarafından ülkemiz içinde ulusal kanser kayıt veri tabanı oluşturulmuştur. Daha sonraki çalışmalarda bu veri tabanı kullanılarak ulusal bildirimin yapılabileceğini; böylece çocukluk çağında baş ve boyun bölgesinde görülen kanserlerin insidansı hakkında daha kesin veri sağlababileceğini, ayrıca baş boyun bölgesinde nedeni bilinmeyen kitlelerle gelen çocukların erken ve doğru tanınarak daha iyi sonuçlara ulaşılabileceğini düşünmekteyiz.

\section{KAYNAKLAR}

Akyüz, C., Sarı, N., Kutluk M.T., Varan, A., Yalçın, B., Büyükpamukçu, M., 2003. Childhood malignant tumors primarly localized in the head and neck region. Int. Society Pediatr. Oncol. SIOP XXXV Meeting, pp 346

Albright, T.J., Topham, A.K., Reilly, J.S. 2002. Pediatric Head and neck malignancies. Arch. Otolaryngol. Head Neck Surg. 128, 655-659

Anselmo, A.D., Cartoni, C., Bellantuono, D., 1990. Risk of infertility in patients with Hodgkin's diseas treated with ABVD vs MOPP vs ABVD/ MOPP. Hematologica. 75, 155-158.

Constine, L.S., Donaldson, S.S., Mc dougall, I.R., 1984. Tyroid dysfunction after radiotherapy in children with Hodgkin disease. Cancer. 53, 
878-883

Gosepath, J., Spix, C., Talebloo, B., Blettner, M., Mann, W.J. 2007. İncidence of childhood cancer of the head and neck in Germany. Eur. Society Med. Ann Oncol. 18, 1716-1721.

Hudson, M.M., Onciu, M., Donaldson, S.S. 2006. Hodgkin's lymphoma. In: Pizzo PA, Poplack DG (eds). Principles and Practice of Pediatric Oncology, Lippincott Williams \& Wilkins, Philadelphia, 695-721.

Karayalçı, G., 2000. Hodgkin's disease. In: Lanzkowsky P(ed).In: Manual of Pediatric Hematology and oncology, Third edition, San Diego, California, 413-443.

Khademi, B., Taraghi, A., Mohammadianpanah, M. 2009. Anatomical and histopatological profile of head and neck neoplasm in Persian pediat ric and adolescent population. Int. J. Pediatr. Otorhinolaryngol. 73, 1249-1253

Whittemore, K.R., Cunningham, M.J. 2003. Cancer of the head and neck in the pediatric population. In: Cancer of the Head and Neck, EN Myers, JY Suen, JN Myers, EYN Hanna (eds), 4th ed., Saunders, Philadelphia, 